\title{
An Anterior Primary Myxoid Liposarcoma Case
}

\author{
Ercan Kurtipek ${ }^{1}$, Hıdır Esme ${ }^{2}$, Taha Tahir Bekçi ${ }^{1}$, Mihrican Yeşildağ $\breve{g}^{1}$ \\ Burhan Apilioğulları ${ }^{3}$
}

${ }^{1}$ Clinic of Chest Diseases, Konya Training and Research Hospital, Konya
${ }^{2}$ Clinic of Chest Surgery, Konya Training and Research Hospital, Konya
${ }^{3}$ Clinic of Chest Surgery, Necmettin Erbakan University Faculty of Medicine, Konya

\section{Abstract}

Liposarcomas (LPS) account for approximately $15 \%$ of all sarcomas among mesenchymal neoplasms and $6 \%$ of primary mediastinal tumors. LPS, usually found in the lower extremities or retroperitoneum, have also been reported in the abdomen, vulva, and buttocks. However, primary LPS of the anterior mediastinum are extremely rare. In this paper, we present a case of a fast progressing metastatic primary myxoid liposarcoma of the anterior mediastinum.

Keywords: Chemoradiotherapy, liposarcoma, mediastinum, myxoid

Received Date: 27.11.2013 Accepted Date: 23.02.2014 Available Online Date: 13.02 .2015

Address for correspondence Ercan Kurtipek

E-mail: kurtipek14@hotmail.com

(c) (1) $\begin{aligned} & \text { This work is licensed under a Creative } \\ & \text { Commons Attribution-NonCommercial }\end{aligned}$ 4.0 International License.

DOI: 10.5152/ejp.2014.29895

-Available online at www.eurasianjpulmonol.com

\section{INTRODUCTION}

Liposarcomas (LPS) account for approximately 15\% of all sarcomas among mesenchymal neoplasms and comprise $6 \%$ of primary mediastinal tumors (1-3). LPS are generally found in the lower extremities or retroperitoneum, but they have also been reported in the abdomen, vulva, and buttocks. However, primary LPS of the anterior mediastinum are extremely rare (2). Myxoid LPS composed of round cells with differing lipoblastic differentiation in an abundantly myxoid vascular background is the second most prevalent subtype of liposarcoma $(4,5)$. Surgery remains the primary therapeutic modality. Different pathological subtypes may present with different epidemiological features and biological behaviors. Recent advances in genetic characterization of LPS indicate four histogenetic types. These are well-differentiated/dedifferentiated, myxoid, pleomorphic, and unclassified liposarcoma (6). An important prognostic factor is the pathological subtype determined. We present a fast progressing metastatic primary myxoid liposarcoma of the anterior mediastinum, which resulted in an exitus within nine months and discuss its clinical, imaging, and pathological aspects by reviewing relevant current literature. Written informed consent was obtained from a first-degree relative of the patient.

\section{CASE PRESENTATION}

A 46-year-old non-smoking female patient presented to our outpatient department with mild chest and back pain. She reported no shortness of breath or weight loss. She had no significant medical or family history. Her physical examination and laboratory results were unremarkable. Her chest X-ray showed an upper mediastinal enlargement on the right paratracheal area, and her chest computed tomography (CT) scan confirmed a mediastinal mass of $80 \times 50 \mathrm{~mm}$ located in the right upper anterior mediastinum (Figure 1, 2). The mass had a necrotic center and an invasion into the superior vena cava and brachiocephalic trunk. An ultrasound-guided fine needle aspiration was performed from the tumor.

The pathological study revealed myxoid stroma and a visible rich vascular structure with thin branches, vacuolated cytoplasm, pleomorphic lipoblast type cells, and mitotic figures with atypical cells. Immunohistochemical analysis with Vimentin and S-100 showed positive staining (Figure 3). The final pathological diagnosis was myxoid liposarcoma. 
After the pathological diagnosis, positron emission tomography (PET)/CT scan was performed, displaying a mass of $77 \times 60 \times 71 \mathrm{~mm}$ of heterogeneous character and soft tissue density with a standardized uptake value of a maximum of 4.49. There were no other pathological findings.

Surgical intervention was ruled out because the mass had a necrotic center and invasion into the superior vena cava and brachiocephalic trunk. In line with the decision of the Oncology Board, chemoradiotherapy was considered the most appropriate treatment modality.

Because chemotherapy would increase the effectiveness of radiotherapy, the patient underwent concomitant chemotherapy and radiotherapy. She received standard doses of chemotherapy, including adriamycin $\left(60 \mathrm{mg} / \mathrm{m}^{2}\right)$ and ifosfamide $\left(2.5 \mathrm{~g} / \mathrm{m}^{2}\right)$ in two cycles. Radiotherapy was performed after calculation of the dosage using the

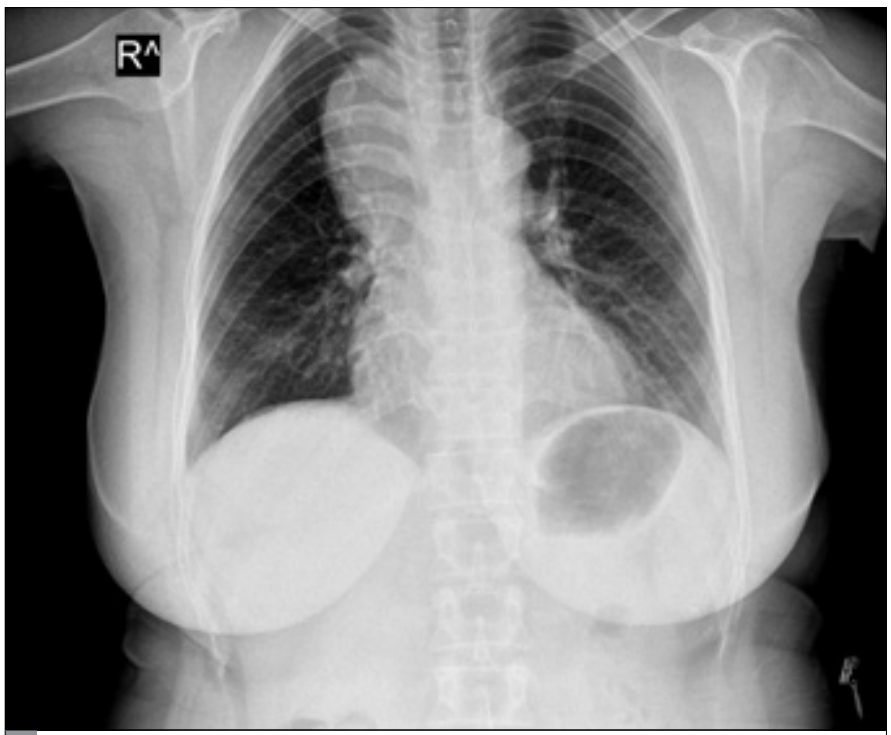

Figure 1. Plain chest $\mathrm{X}$-ray image of the patient indicating a mass at the upper right mediastinal zone

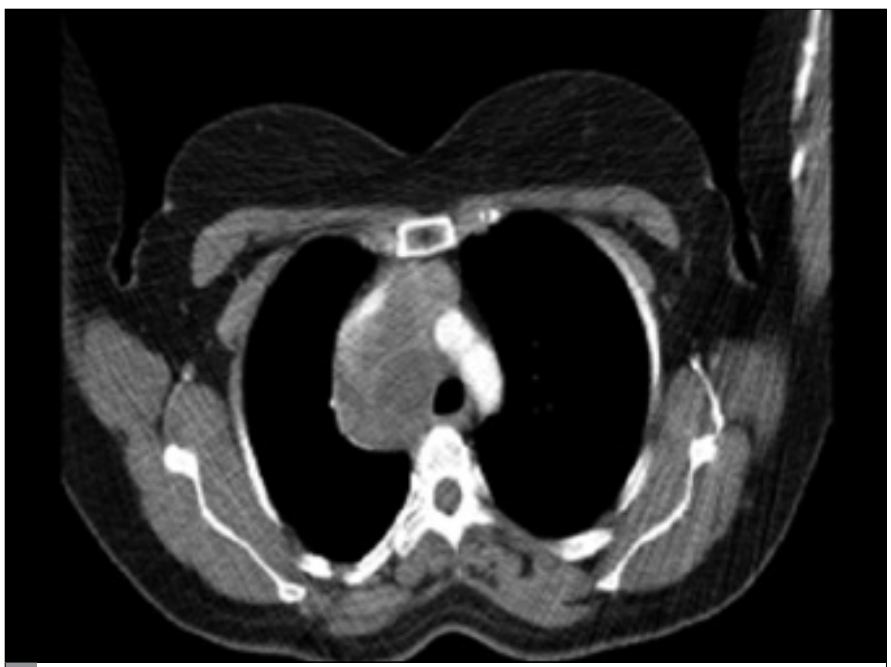

Figure 2. Patient's representative axial computed tomography image before the treatment indicating a mediastinal mass of 80 $x 50 \mathrm{~mm}$ in size and located in the right upper and anterior mediastinum invading vena cava and brachiocephalic trunk intensity-modulated radiation therapy (IMRT) technique daily at 200 cGy per fraction in 25 fractions to a total dose of 5000 cGy applied externally to the approximately $8 \mathrm{~cm}$ mass in the mediastinum. Six weeks after the radiotherapy, a CT scan was performed (Figure 4). The CT scan revealed neither shrinkage nor further progression after the treatment. Based on the outcome, she was regarded as a stable patient without any partial or complete response, showing neither a decline nor an increase in the tumor size. She broke her appointments for monthly control even though she was urged not to do so. She instead sought alternative herbal treatment for five months before she showed up again; however, by then, she already had distant liver metastasis (Figure 5). The chest CT scan showed multiple metastases in both lobes, the largest one measuring $43 \times 38 \mathrm{~mm}$ in the left lobe of the liver.

Based on this, the patient received only one dose of a second-line combination chemotherapy, including gemcitabine $\left(900 \mathrm{mg} / \mathrm{m}^{2}\right)$

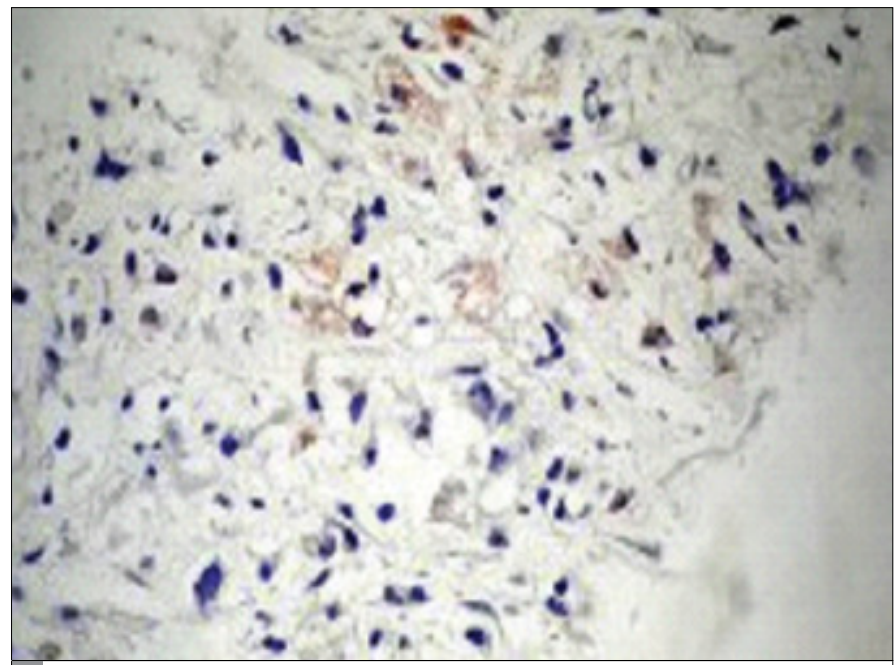

Figure 3. High power view (H\&E x 400) showing myxoid stroma and rich visible vascular structure with thin branches, vacuolate cytoplasm, pleomorphic lipoblast type cells, and mitotic figures with atypical cells stained with Vimentin and S-100 for immunohystochemical analysis

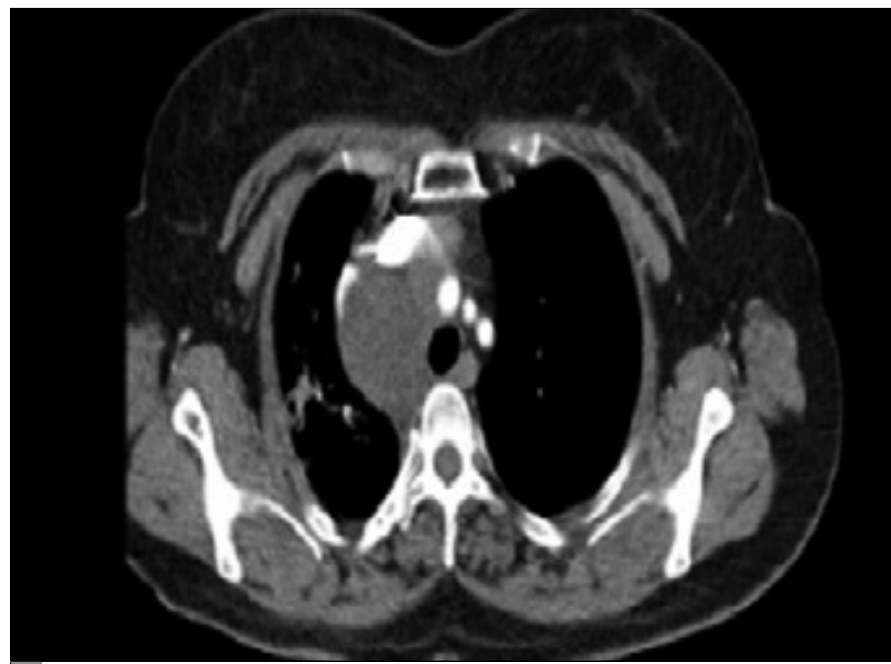

Figure 4. Patient's representative axial computed tomography image after the treatment indicating a mediastinal mass approximately the same size as before 
and docetaxel $\left(60 \mathrm{mg} / \mathrm{m}^{2}\right)$. Despite treatment for liver metastasis, the patient showed a rapid progression (Figure 6). The number and size of the metastases rapidly increased in both lobes, the largest one measuring approximately $8 \mathrm{~cm}$. The patient died three months after the detection of the liver metastasis.

\section{DISCUSSION}

LPS usually occur in the deep soft tissues of the lower extremities and retroperitoneum and are seldom found in the mediastinum (3). Boland et al. (6) studied 24 cases. According to the clinicopathological analysis made by Hahn and Fletcher (7), among the 24 patients, only two were categorized as myxoid liposarcoma, whereas nine had liposarcoma in the anterior mediastinum. Liposarcoma in the mediastinum is rarely seen. In Turkey, till date, there are three reported mediastinal liposarcoma cases that were reported by Yekeler et al. (8), Düzgün et al. (9) and Ağca et al. (10). Similarly, cases with anterior mediastinal liposarcoma are

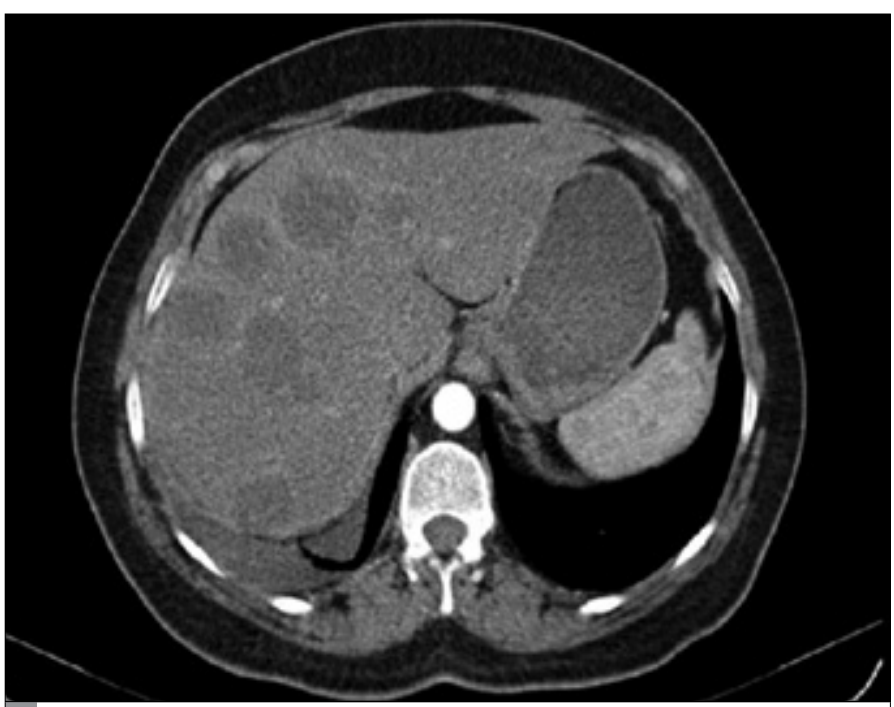

Figure 5. Chest CT- scan showed in both liver lobes multiple distant metastases with the biggest one in the left lobe of the liver of $43 \times 38 \mathrm{~mm}$

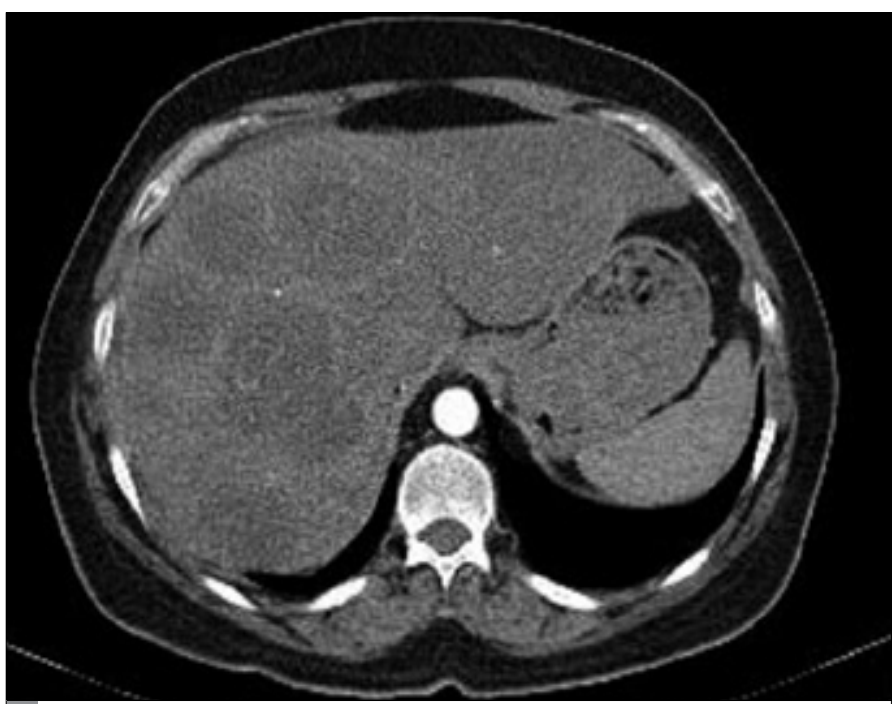

Figure 6 . The number and size of the metastases have rapidly increased in both liver lobes with the biggest one of $8 \mathrm{~cm}$ rare worldwide, according to the relevant literature (11), which led us to report the present case. In a review by Schweitzer et al. (12), $63 \%$ of patients presented with respiratory symptoms, $50 \%$ with chest pain, and $15 \%$ with superior vena cava obstruction. The presenting symptoms included chest pain, dyspnea, cough, and superior vena cava syndrome, which were associated with compression to the adjacent organs. Commonly, such patients tend to be asymptomatic, and most of them are diagnosed by routine chest $X$-rays that show mass shadows (3). In the present case, our patient had an insignificant chest and back pain for the last three months before the diagnosis was made. There were no other symptoms. The routine $\mathrm{X}$-ray chest image revealed a mass on the right upper zone. Because of this, the patient underwent further diagnostic intervention. Liposarcoma of the anterior mediastinum is usually removed by total resection. Although there is a general tendency to manage mediastinal liposarcoma with surgery, it was inappropriate because of the invasion of two major mediastinal vessels in the current case, and chemoradiotherapy was preferred.

Principles of treatment include surgical resection and adjuvant radiochemotherapy. Despite multimodality therapy, the prognosis continues to be poor $(2,13)$.

Myxoid liposarcoma is most often composed of bland round cells with variable lipoblastic differentiation scattered in an abundantly myxoid, highly vascular background. Rarely, a myxoid liposarcoma shows extensive mature adipocytic differentiation (differentiated myxoid liposarcoma). High grade myxoid liposarcoma (round cell liposarcoma) shows markedly increased cellularity, elevated nuclear grade, high mitotic activity, and loss of myxoid matrix. In the present case, there might as well have been a vascular invasion. In this case, the mass had a necrotic center and an invasion into the superior vena cava and brachiocephalic trunk. The present findings ruled out surgical intervention. In line with the decision of the Oncology Board, chemoradiotherapy was considered as the most appropriate treatment modality. No shrinkage was observed in the tumor size as a result of chemotherapy. Initially, the patient was considered as stable, showing neither a decline nor an increase in the tumor size. However, she developed distant liver metastasis after five months, resulting in an exitus within nine months after the diagnosis of mediastinal LPS. Mediastinal liposarcoma is a rare disease. Surgery is the primary therapeutic modality. Different pathological subtypes may present with different epidemiological features and biological behaviors. An important prognostic factor is the pathological subtype determined. Well-differentiated tumors can have a better prognosis compared with other subtypes. Despite multimodality therapy, as in the present case, the prognosis continues to be poor unless there is surgical intervention (13). As stated by Boland et al. (6), patients with myxoid liposarcoma, like in our case, have a faster disease progression with a fatal outcome.

\section{CONCLUSION}

Myxoid mediastinal liposarcoma is a rare tumor with a good prognosis if it can be surgically removed. The progression is quite fast with a significantly higher mortality rate in cases without surgical intervention. Hence, these patients have to undergo surgical intervention as quickly as possible. 
Informed Consent: Informed consent was obtained from patient who participated in this case.

Peer-review: Externally peer-reviewed.

Author contributions: Concept - E.K.; Design - B.A., E.K.; Supervision - T.T.B.; Resource - M.Y.; Materials - H.E.; Data Collection \&/or Processing - E.K.; Analysis \&/or Interpretation - E.K., H.E.; Literature Search - E.K.; Writing - E.K.; Critical Reviews - E.K.

Conflict of Interest: No conflict of interest was declared by the authors.

Financial Disclosure: The authors declared that this study has received no financial support.

\section{REFERENCES}

1. Raghavan R, Raghuram P, Parekh PV, Kurien JM. Posterior mediastinal liposarcoma simulating along mass: an unusual case report. Cancer Imaging 2007; 7: 141-4. [CrossRef]

2. Hirai S, Hamanaka Y, Mitsui N, Uegami S, Matsuura Y. Surgical resection of primary liposarcoma of the anterior mediastinum. Ann Thorac Cardiovasc Surg 2008; 14: 38-41.

3. Chiyo M, Fujisawa T, Yasukawa T, Shiba M, Shibuya K, Sekine Y, et al. Successful resection of a primary liposarcoma in the anterior mediastinum in a child: report of a case. Surg Today 2001; 31:230-2. [CrossRef]

4. Fletcher CD, Akerman M, Dal Cin P, de Wever I, Mandalh N, Mertens F, et al. Correlation between clinicopathological features and karyotype in lipomatous tumors. A report of 178 cases from the Chromosomes and Morphology (CHAMP) Collaborative Study Group. Am J Pathol 1996; 148: 623-30.
5. Weiss SW, Goldblum JR. Enzinger and Weiss's Soft Tissue Tumors. Mosby: Elsevier; 2008.

6. Boland JM, Colby TV, Folpe AL. Liposarcomas of the mediastinum and thorax. a clinicopathologic and molecular cytogenetic study of 24 cases, emphasizing unusual and diverse histologic features. Am J Surg Pathol 2012; 36: 1395-403. [CrossRef]

7. Hahn HP, Fletcher CD. Primary mediastinal liposarcoma: clinicopathologic analysis of 24 cases. Am J Surg Pathol 2007; 31: 1868-74. [CrossRef]

8. Yekeler $\mathrm{E}$, Ulutas $\mathrm{H}, \mathrm{Ozmen} \mathrm{SA}$. A giant primary liposarcoma of the anterior mediastinum. Journal of Clinical and Analytical Medicine 2012. Online published.

9. Düzgün S, Yılmaz A, Selvi A, Somay A. Primer mediastinal liposarkom Solunum 2002; 4: 264-7.

10. Ağca M, Arınç S, Yaldız E, Yılmaz A, Kutlu A, Karagöz T. Mediastinal liposarkoma olgusu. Solunum 2008; 10: 206-8.

11. Attal H, Jensen J, Reyes CV. Myxoid liposarcoma of the anterior mediastinum. Diagnosis by fine needle aspiration biopsy. Acta Cytol 1995; 39: 511-3.

12. Schweitzer DL, Aquam AS. Primary liposarcoma of the mediastinum. Report of a case and review of the literature. JThorac Cardiovasc Surg 1977; 74: 83-97.

13. Guadagnolo BA, Zagars GK, Ballo MT, Patel SR, Lewis VO, Benjamin RS, et al. Excellent local controlrates and distinctive patterns of failure in myxoid liposarcoma treated with conservation surgery and radiotherapy. Int J Radiat Oncol Biol Phys 2008; 70: 760-5. [CrossRef] 